\title{
Uranium targets for heavy-ion accelerators
}

\author{
Bettina Lommel*, Elif Celik Ayik, Annett Hübner, Birgit Kindler, Jutta Steiner, and Vera Yakusheva \\ GSI Helmholtzzentrum für Schwerionenforschung, Targetlabor, Planckstrasse 1,64291 Darmstadt, Germany
}

\begin{abstract}
Uranium targets are very important for accelerator-based research of nuclear properties. Depending on the reaction to be studied and on the conditions during the experiments different restrictions on the target material have to be met; as for example, durability, melting temperature, reactivity or a possible contribution of the additional compounds present to the reaction. Therefore, we are developing processes to produce uranium targets in the elemental form as well as in different compounds.

Here we report on the production and application of targets from metallic uranium, $\mathrm{UF}_{4}$ and $\mathrm{UO}_{2}$.
\end{abstract}

\section{Introduction}

Uranium is a commonly used target for acceleratorbased research on nuclear properties. While uranium and uranium tetrafluoride $\left(\mathrm{UF}_{4}\right)$ have a melting point significantly above $1000 \mathrm{~K}$, uranium oxide $\left(\mathrm{UO}_{2}\right)$ and uranium carbide (UC) have a significantly higher melting point above $2000 \mathrm{~K}$. For high-intensity beams, targets of higher melting compounds are better suited. Metallic uranium oxidizes easily in (humid) air. As most of the commercially available metallic uranium has already some oxygen component, additional oxidation cannot not be hindered, even when kept under inert gas. Therefore, only a target of a high-melting uranium compound, which is stable in air, guarantees for longlasting stability.

\section{Starting material}

Uranium and all its compounds are highly toxic, radioactive, accumulate in inner organs and endanger the environment. From uranium, only radioactive isotopes are known. In the target laboratory at GSI, we apply only ${ }^{238} \mathrm{U}$. The radioactive laboratory of the target laboratory has an allowance for uranium, which is depleted from natural uranium and has a depletion of below $0.4 \%{ }^{235} \mathrm{U}$. For our own safety, we work with material depleted lower than $0.2 \%{ }^{235} \mathrm{U}$, typically. Beside the pure metal, the carbide, fluoride and oxide are an option because of their better stability in air. In the following, we describe the different starting materials and their availability on the market.

\subsection{Metallic uranium}

Metallic uranium can be obtained as a sputter target or as evaporation material from Framatome [1], Manufacturing Sciences Corporation [2], or SC Chepetsky Mechanical Plant [3]. Physical vapour deposition from a boat or from a crucible is difficult, as uranium forms numerous compounds, and therefore crucibles are destroyed easily. Physical vapour deposition with the electron-beam gun has a very low yield. Although this method was applied in the past [4], methods with less wasteful consumption of radioactive materials are preferable. Metallic uranium targets on backings can be obtained by DC-magnetron sputtering [5].

\subsection{Uranium tetrafluoride $\left(\mathrm{UF}_{4}\right)$}

Uranium tetrafluoride $\left(\mathrm{UF}_{4}\right)$ can be deposited with physical vapour deposition from the tantalum boat or from the tantalum crucible [5]. The material is stable in dry air. The material is no longer commercially available in Europe, but we still have remaining stock bought in the past from Merck Company [6].

\subsection{Uranium oxide $\left(\mathrm{UO}_{2}\right)$}

Uranium oxide $\left(\mathrm{UO}_{2}\right)$ can be deposited with physical vapour deposition from the electron-beam gun. Physical vapour deposition with the electron-beam gun has a very low yield. Although this method was applied in the past [7], methods with less wasteful consumption of radioactive materials are preferable. We succeeded in obtaining uranium oxide as a hot pressed 1"-sputter target.

\subsection{Uranium carbide (UC)}

Uranium carbide (UC) is an interesting target material, as well. Uranium carbide has a high melting point of $\mathrm{T}_{\mathrm{m}}=2500 \mathrm{~K}$. It is available in different compounds, UC would be the material of our choice, since the other carbides are difficult to be obtained in a stoichiometric compound and some decompose during heating. A sputter target out of UC is commercially not available.

\footnotetext{
* Corresponding author: B.Lommel@gsi.de
} 


\section{Physical vapour deposition}

In the target laboratory at GSI electron-beam gun deposition, thermal deposition, resistance heating, DCmagnetron sputtering and RF-magnetron sputtering are the methods available for target fabrication. Deposition with an electron-beam gun has a yield of about $5 \%$ for homogenous layers. This is not an option for the deposition of radioactive material. Thermal deposition is an option for uranium tetrafluoride with its melting point of $\mathrm{T}_{\mathrm{m}}=1300 \mathrm{~K}$ and crucibles out of tantalum or platinum are available. Uranium oxide and uranium carbide can only be processed with an electron-beam gun or a sputtering set-up. Insulating materials are sputtered with RF-magnetron sputtering; conductive materials are sputtered with DC-magnetron sputtering. For materials with a known poor electrical conductivity, the sputter ability with a DC-magnetron has to be tested experimentally.

\subsection{Thermal deposition of $\mathrm{UF}_{4}$}

Uranium tetrafluoride $\left(\mathrm{UF}_{4}\right)$ can be deposited with physical vapour deposition from the tantalum boat or from the tantalum crucible [5]. We apply a tantalum crucible to deposit up to $500 \mu \mathrm{g} / \mathrm{cm}^{2}$ uranium fluoride on carbon backing up to a diameter of $30 \mathrm{~mm}$, respectively. We obtain uranium fluoride layers with a homogeneity of $\pm 5 \%$. The targets are stable in dry air. Depending on the application, the targets are covered with a carbon layer to hinder the sputtering in the beam [5].

\subsection{DC-magnetron sputtering of metallic $U$}

Metallic uranium can be deposited by DC-magnetron sputtering from a water-cooled 1"-copper magnetron [5]. We deposit metallic uranium on $\mathrm{Be}, \mathrm{C}, \mathrm{Al}, \mathrm{Ti}, \mathrm{Nb}$ and Ta backings up to a thickness of $2000 \mu \mathrm{g} / \mathrm{cm}^{2}$ and up to a diameter of $30 \mathrm{~mm}$. We obtain uranium layers with a homogeneity of $\pm 5 \%$. The targets oxidize easily under air, even quicker under humid air. Depending on the oxygen content of the starting material the oxidation in an argon glove box cannot be hindered, naturally it slows down but after weeks of storage the uranium is affected as well. Depending on the application, the targets are covered with a carbon layer to hinder the sputtering in the beam. The carbon covering layer does not hinder the oxidation.

\subsection{DC-magnetron sputtering of $\left(\mathrm{UO}_{2}\right)$}

Uranium oxide can be deposited by DC-magnetron sputtering from a water-cooled 1"-copper magnetron. We deposit $\mathrm{UO}_{2}$ on carbon backings as well as on titanium backings with a thickness of up to $2000 \mu \mathrm{g} / \mathrm{cm}^{2}$ and up to a diameter of $30 \mathrm{~mm}$. We obtain uranium layers with a homogeneity of $\pm 5 \%$. The targets are stable in dry air.

The uranium oxide sputter target is a hot sintered ceramic material with poor thermal conductivity. For the sputtering of uranium oxide a rather high power of about
$150 \mathrm{~W}$ is needed. Therefore, the process is divided into steps of 2 minutes sputtering time to avoid overheating and to give the set-up time for cooling down after each step.

To obtain a thickness of about $2500 \mu \mathrm{g} / \mathrm{cm}^{2}$ in total 400 minutes of sputtering are needed. A denser sputtering target, which is produced by hot powder metallurgy or another compound, can be an alternative.

\subsection{Physical vapour deposition (PVD) of UC}

We are planning to obtain uranium carbide as a sputter target. We assume that uranium carbide can be sputtered with a DC-magnetron system.

\section{Application of the obtained targets}

The uranium oxide targets will be applied in experiments of nuclear structure at GSI in Germany, at ELI in Romania and at SARAF in Israel.

\section{References}

1. www.framatome.com

2. mfgsci.com/

3. www.chmz.net

4. H. Folger, W. Hartmann, J. Klemm and W. Thalheimer, Nucl. Instr. and Meth. A 28273 (1989)

5. B. Kindler, D. Ackermann, W. Hartmann, F. P. Heßberger, S. Hofmann, A. Hübner, B. Lommel, R. Mann and J. Steiner, Nucl. Instr. and Meth. A 590 126 (2008)

6. www.merckgroup.com

7. J. G. Povelites, Report AERE-R 5097 (1965) 